\title{
Simultaneous determination of methoxyflavones in selected Korean thistles
}

\author{
Joyce P. Rodriguez ${ }^{1} \cdot$ Norman G. Quilantang $^{1} \cdot J_{u}$ Sung Lee $^{1} \cdot J_{u n}$ Yeon Park ${ }^{2} \cdot$ Jae Suk Shim $^{3}$ \\ - Ki Sung Kang ${ }^{4} \cdot$ Eun Ju Cho ${ }^{5}$ Paul John L. Geraldino ${ }^{6} \cdot$ Sanghyun Lee $^{1}$ (D)
}

Received: 26 June 2018 / Accepted: 17 July 2018 / Published Online: 30 September 2018

(C) The Korean Society for Applied Biological Chemistry 2018

\begin{abstract}
Simultaneous determination of three methoxyflavones, namely, cirsimarin (1), hispidulin (2), and cirsimaritin (3) in selected Korean thistles was performed via reversed-phase high performance liquid chromatography system. Compound $\mathbf{1}$ was present in all the thistle species examined, whereas $\mathbf{2}$ and $\mathbf{3}$ were only detected in Cirsium japonicum and C. japonicum var. maackii (CJM). The concentration of compounds 1-3 in CJM varied according to the time of harvest. Plants collected in the spring (CJMS) and fall (CJMF) had the highest contents of $\mathbf{3}$ and 1, respectively. A lower content of $\mathbf{2}$ was observed in CJMF than in CJMS. This indicates that seasonal variation affects the flavonoid content of CJM. The results of this study show that CJM is an excellent source of compounds 1-3 and it can potentially be cultivated for industrial and pharmaceutical applications involving these compounds.
\end{abstract}

J.P. Rodriguez and N.G. Quilantang equally contributed this article.

Sanghyun Lee $(\bowtie)$

E-mail: slee@cau.ac.kr

${ }^{1}$ Department of Integrative Plant Science, Chung-Ang University, Anseong 17546, Republic of Korea

${ }^{2}$ Department of Food Science and Biotechnology, Kyonggi University, Suwon 16227, Republic of Korea

${ }^{3}$ Imsil Herbal Medicine Association, Imsil 55955, Republic of Korea

${ }^{4}$ College of Korean Medicine, Gachon University, Seongnam 13120, Republic of Korea

${ }^{5}$ Department of Food Science and Nutrition, Pusan National University, Busan 46241, Republic of Korea

${ }^{6}$ Department of Biology, University of San Carlos, Cebu 6000, Philippines

This is an Open Access article distributed under the terms of the Creative Commons Attribution Non-Commercial License (http://creativecommons org/licenses/by-nc/3.0/) which permits unrestricted non-commercial use, distribution, and reproduction in any medium, provided the original work is properly cited.
Keywords Cirsimarin - Cirsimaritin - High performance liquid chromatography-UV $\cdot$ Hispidulin $\cdot$ Korean thistles $\cdot$ Methoxyflavone

\section{Introduction}

Thistles are perennial plants belonging to the Astraceae family that are characterized by their distinct spiny lanceolate leaves, and flowers with colors ranging from white to purple. There are approximately 250 thistle species distributed worldwide and ten of them are found in Korea [1]. They are traditionally used for herbal medicine preparations that include treatments for liver diseases, hemorrhage, edema, and inflammation [2,3]. Recent studies have revealed that thistles are rich in many bioactive compounds such as terpenoids, phytosterols, fatty acids, alkaloids, and flavonoids [4-7]. Particularly, flavonoids isolated from this genus have been shown to possess various biological activities. For example, pectolinarin and apigenin isolated from Cirsium japonicum exhibited anti-tumor and anti-excitotoxic activities in mice, respectively; pectolinarigenin from $C$. setidens exerted hepatoprotective and neuroprotective effects, and luteolin-5- $O$-glucoside displayed antiinflammatory effects [8-12].

In our previous study, three methoxyflavones, namely, cirsimarin (1), hispidulin (2), and cirsimaritin (3) were isolated from the aerial parts of $C$. japonicum var. maackii (CJM) [13,14]. These compounds have been shown to exhibit bioactive properties, and thus have pharmacological importance [15-18]. Accordingly, the aim of this study was to determine the distribution of these compounds and quantify their contents in selected Korean thistles by high performance liquid chromatography (HPLC) with ultraviolet-visible detection. The results of this study will serve as a basis for the quality evaluation and selection of Korean thistles to be cultivated for industrial and pharmaceutical applications involving these compounds. 


\section{Materials and Methods}

\section{Plant materials and methanol extracts}

Selected thistle species and varieties were analyzed in the study. C. japonicum var. maackii (CJM) collected during spring $(C$. japonicum var. maackii from spring: CJMS) and fall $(C$. japonicum var. maackii from fall: CJMF) seasons were extracted with methanol $(\mathrm{MeOH})$ at $80{ }^{\circ} \mathrm{C}$ for $3 \mathrm{~h}$ and evaporated to dryness. The $\mathrm{MeOH}$ extracts of samples from several thistle species were procured from the Korea Research Institute of Bioscience and Biotechnology. These samples were from the species: C. japonicum (CJ), C. chlorepsis (CC1), C. chanroenicum (CC2), Carduus crispus (CC3), C. nipponicum (CN), and $C$. setidens (CS).

\section{Instruments and reagents}

HPLC analysis was performed using a Waters HPLC system equipped with a binary pump and a UV-Vis detector (Milford, MA, USA). All solvents used were HPLC grade including, $\mathrm{MeOH}$, acetonitrile $(\mathrm{ACN})$, and water for the analysis.

\section{Preparation of standard and sample solution}

A stock solution containing a mixture of compounds 1-3 was prepared by dissolving $1 \mathrm{mg}$ of each standard compound together in $1 \mathrm{~mL} \mathrm{MeOH}$ (Fig. 1). Serial dilution of the stock solution was performed to obtain the working solutions used for the construction of calibration curves. $\mathrm{MeOH}$ extracts of the selected thistles were prepared by dissolving $20 \mathrm{mg}$ of each extract in 1 $\mathrm{mL} \mathrm{MeOH}$. All samples were filtered with a $0.45-\mu \mathrm{m}$ filter prior to use.

\section{HPLC analytical conditions}

HPLC analysis of compounds 1-3 was performed using a reversed-phase HPLC system utilizing an $\mathrm{INNO}_{18}(25 \mathrm{~cm} \times 4.6$ $\mathrm{mm}, 5 \mu \mathrm{m}$ ) column with a mobile phase of $0.5 \%$ acetic acid-water (solvent A) and ACN (solvent B). The total running time of the analysis was $55 \mathrm{~min}$ and the gradient elution system was performed as follows: $83 \% \mathrm{~A}$ at $0 \mathrm{~min}$, decreased to $70 \% \mathrm{~A}$ between $0-10 \mathrm{~min}$ and maintained until $25 \mathrm{~min}, 20 \% \mathrm{~A}$ at $30 \mathrm{~min}$, increased to $100 \%$ B between 30-35 min and maintained until 40 min, increased to $83 \%$ A between 40-50 min and maintained until $55 \mathrm{~min}$. The flow rate, injection volume, and UV absorbance were $1 \mathrm{~mL} / \mathrm{min}, 10 \mu \mathrm{L}$, and $270 \mathrm{~nm}$, respectively. The temperature of<smiles>[R]c1ccc(-c2cc(=O)c3c(O)c(OC)c([R])cc3o2)cc1</smiles>

\begin{tabular}{ccc}
\hline \hline Compound & $\mathrm{R}_{1}$ & $\mathrm{R}_{2}$ \\
\hline Cirsimarin (1) & $\mathrm{OCH}_{3}$ & $\mathrm{O}-\mathrm{Glc}$ \\
Hispidulin (2) & $\mathrm{OH}$ & $\mathrm{OH}$ \\
Cirsimaritin (3) & $\mathrm{OCH}_{3}$ & $\mathrm{OH}$ \\
\hline
\end{tabular}

Fig. 1 Structures of compounds 1-3

the column was held constant at $30{ }^{\circ} \mathrm{C}$.

\section{Calibration curve}

Calibration curves were constructed by plotting the concentrations of each standard solution with their respective peak areas. The linearity of each calibration curve was determined based on the correlation coefficient $\left(r^{2}\right)$. The concentrations of compounds 1-3 in the samples were calculated from the calibration curve of each compound. The calibration functions were determined based on the peak area $(Y)$, concentration $(X, \mu \mathrm{g} / \mathrm{mL})$, and mean values $(\mathrm{n}=5) \pm$ standard deviation.

\section{Results and Discussion}

The simultaneous determination of compounds 1-3 in selected Korean thistles was performed using a reverse-phase HPLC system. The analytical method showed good linearity as displayed in the calibration curves for each standard compound (Table 1). The chromatographic separation of compounds 1-3 showed a high resolution in all thistles examined (Fig. 2). The peaks of all chromatograms were confirmed by spiking the HPLC samples with the reference compounds and by UV comparison for qualitative analysis. The concentrations and distributions of the methoxyflavones in the samples analyzed are summarized in Table 2. Compound 1 was present in all the thistles examined, and the samples CJMS, CS, CN, and CC2 contained especially high concentrations of the compound. Compounds $\mathbf{2}$ and $\mathbf{3}$ were only detected in CJ, CJMS, and CJMF. Among the thistle species examined, the presence of all three methoxyflavones in CJM is

Table 1 Calibration curves for compounds 1-3

\begin{tabular}{cccc}
\hline \hline Compound & $\mathrm{t}_{\mathrm{R}}{ }^{\mathrm{a}}$ & Calibration equation $^{\mathrm{b}}$ & ${\text { Correlation factor, } r^{2 \mathrm{c}}}^{{ }^{2}}$ \\
\hline Cirsimarin (1) & 17.41 & $\mathrm{Y}=2,000,000 \mathrm{X}+77,179$ & 0.999 \\
Hispidulin (2) & 30.19 & $\mathrm{Y}=2,000,000 \mathrm{X}+14,006$ & 1.000 \\
Cirsimaritin (3) & 32.21 & $\mathrm{Y}=1,000,000 \mathrm{X}+366,477$ & 0.989 \\
\hline
\end{tabular}

$a_{\mathrm{t}_{\mathrm{R}}}=$ retention time

${ }^{b} \mathrm{Y}=$ peak area, $\mathrm{X}=$ concentration of standard $(\mathrm{mg} / \mathrm{mL})$

${ }^{c} r^{2}=$ correlation coefficient for three data points in the calibration curve 


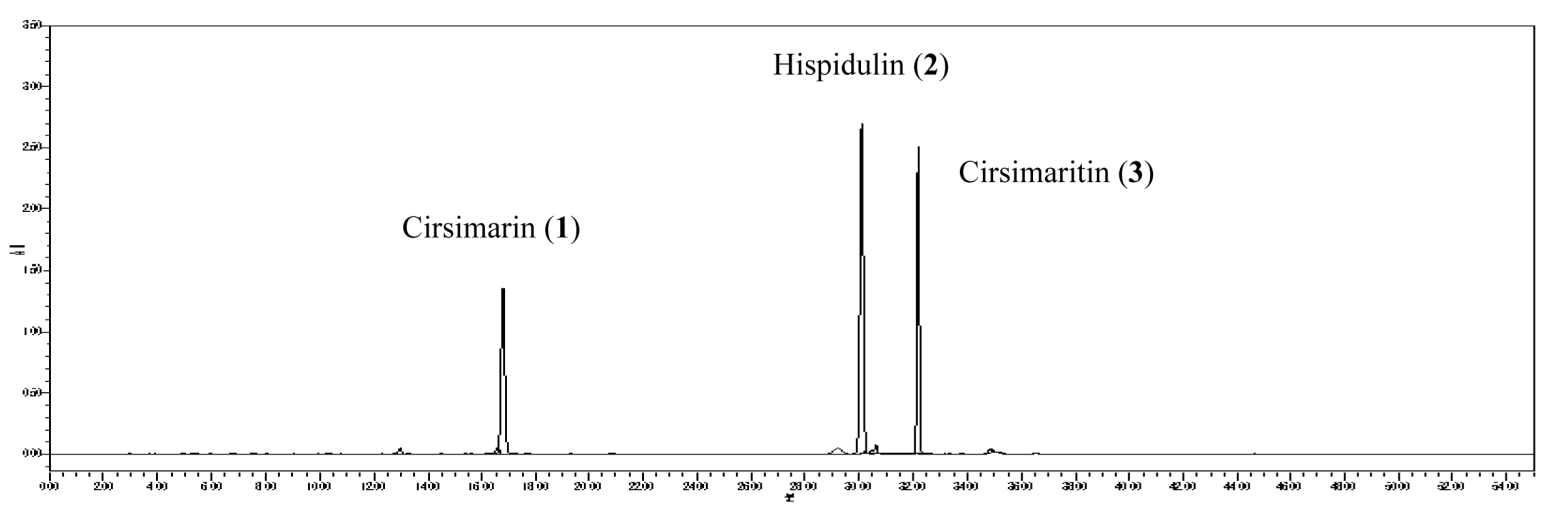

(A)

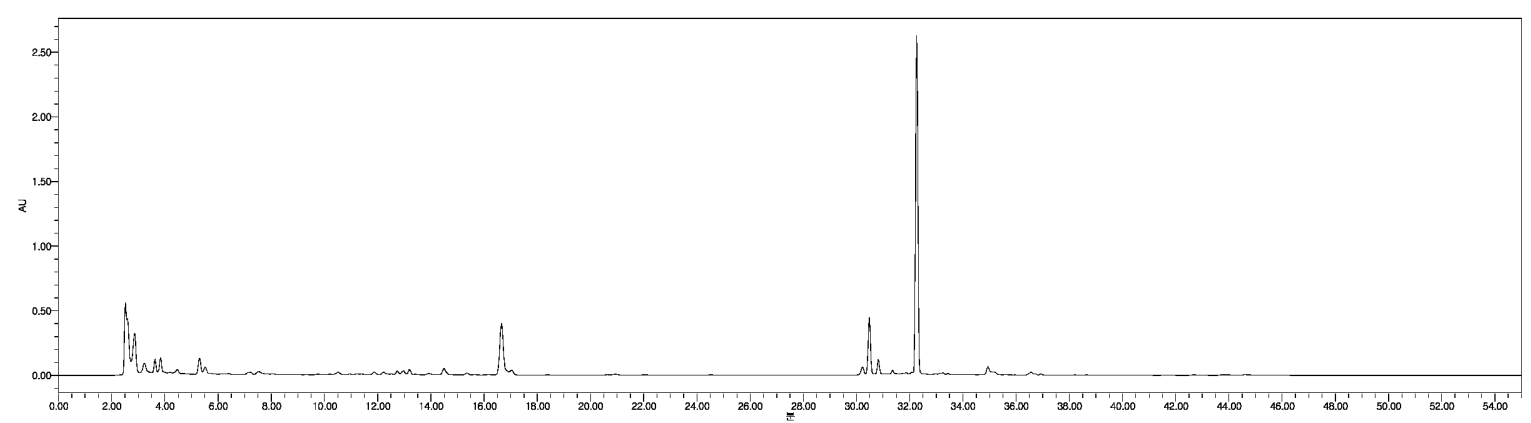

(B)

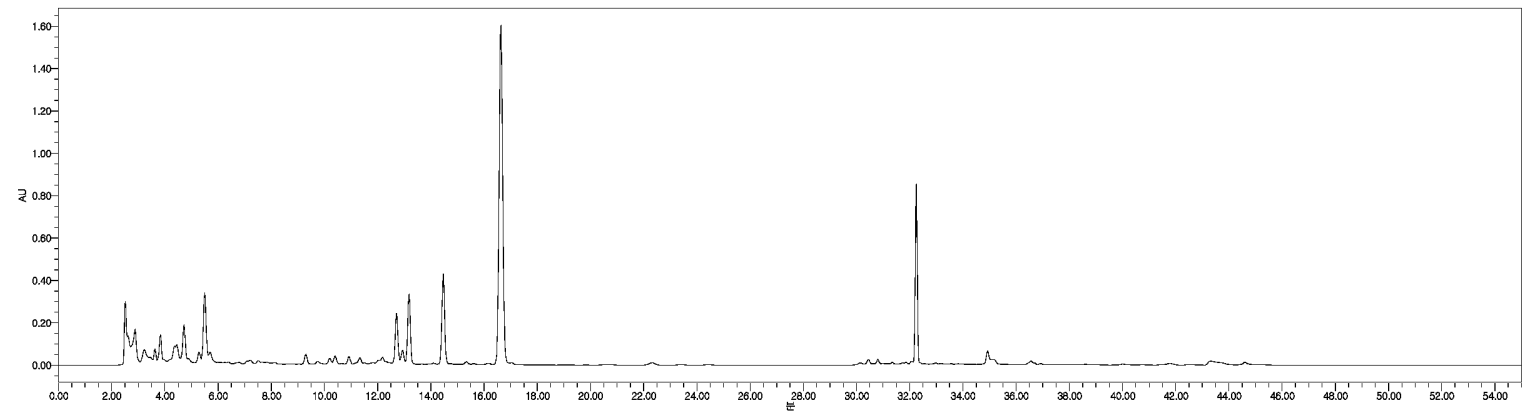

(C)

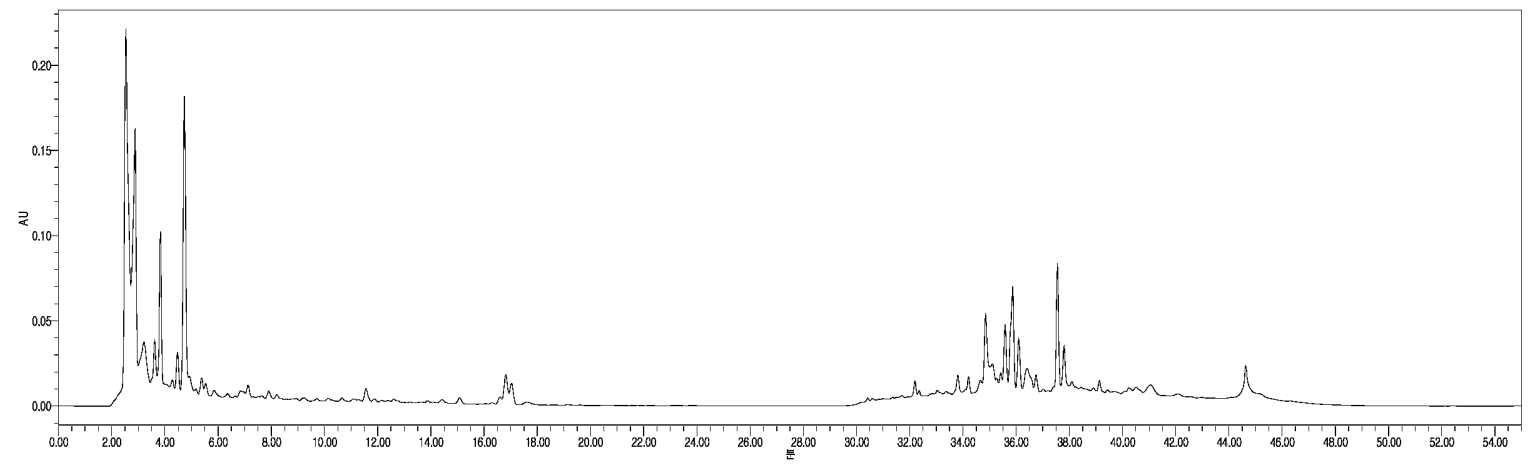

(D)

Fig. 2 HPLC chromatograms of compounds 1-3 (A) and the MeOH extracts of CJMS (B), CJMF (C), CJ (D), CC1 (E), CC2 (F), CC3 (G), CN (H), and CS (I) 


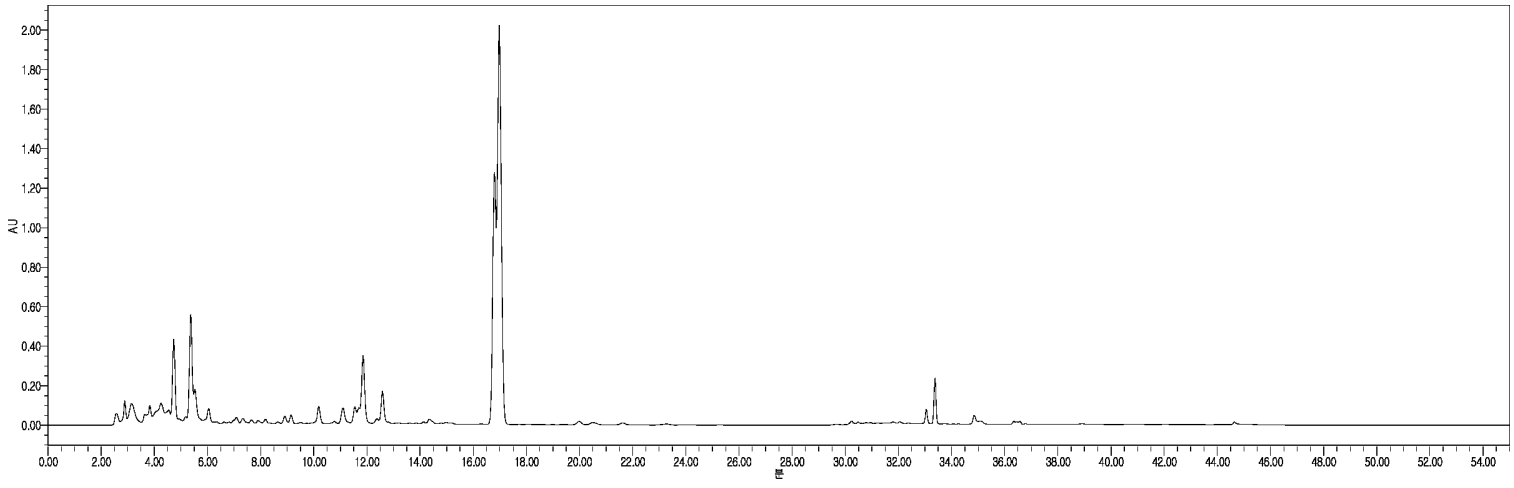

(E)

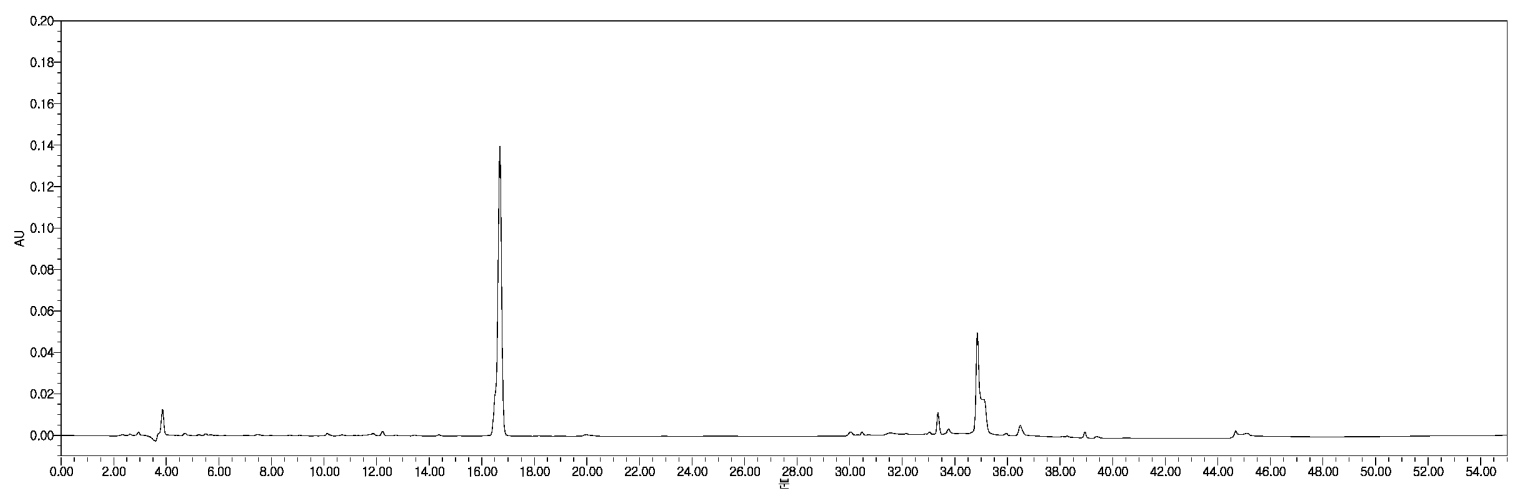

(F)

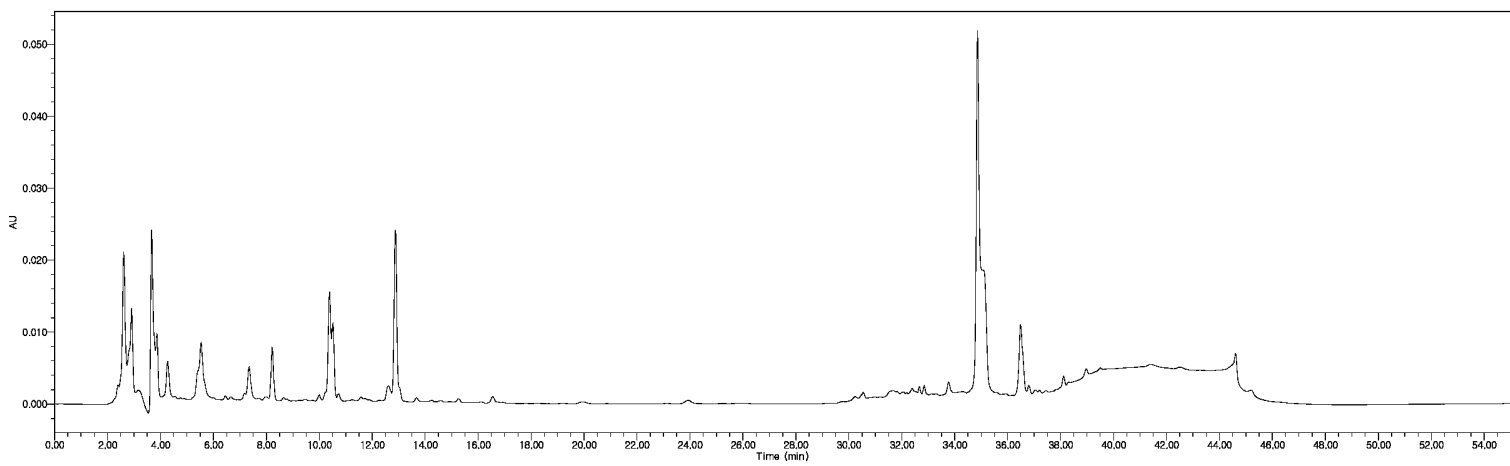

(G)

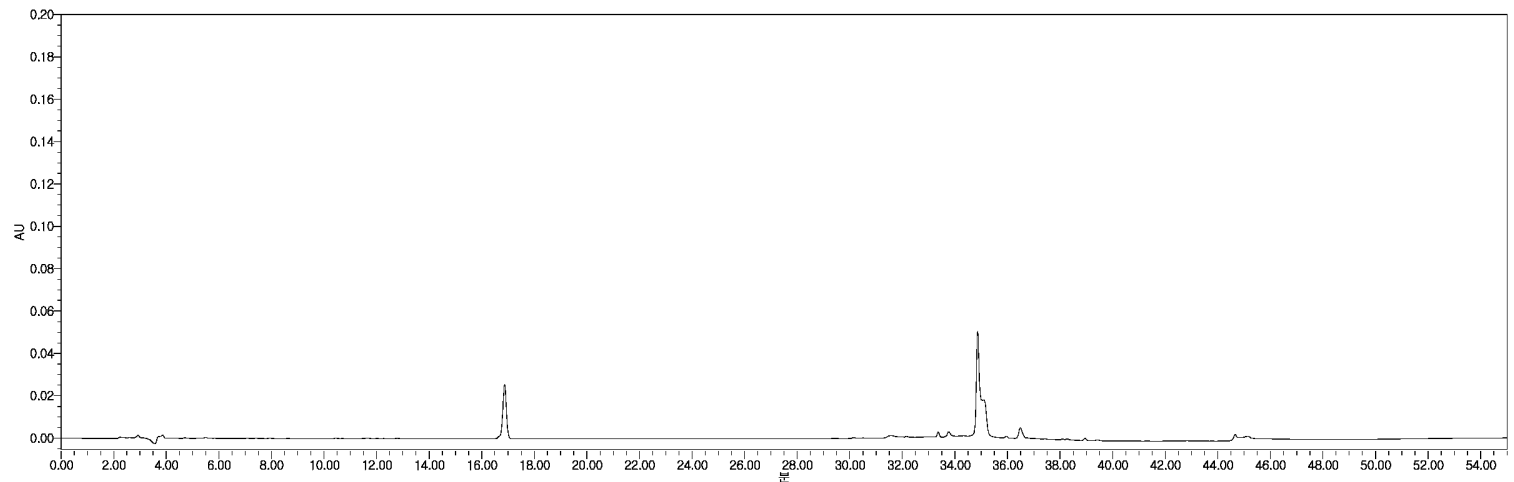

(H)

Fig. 2 Contined 


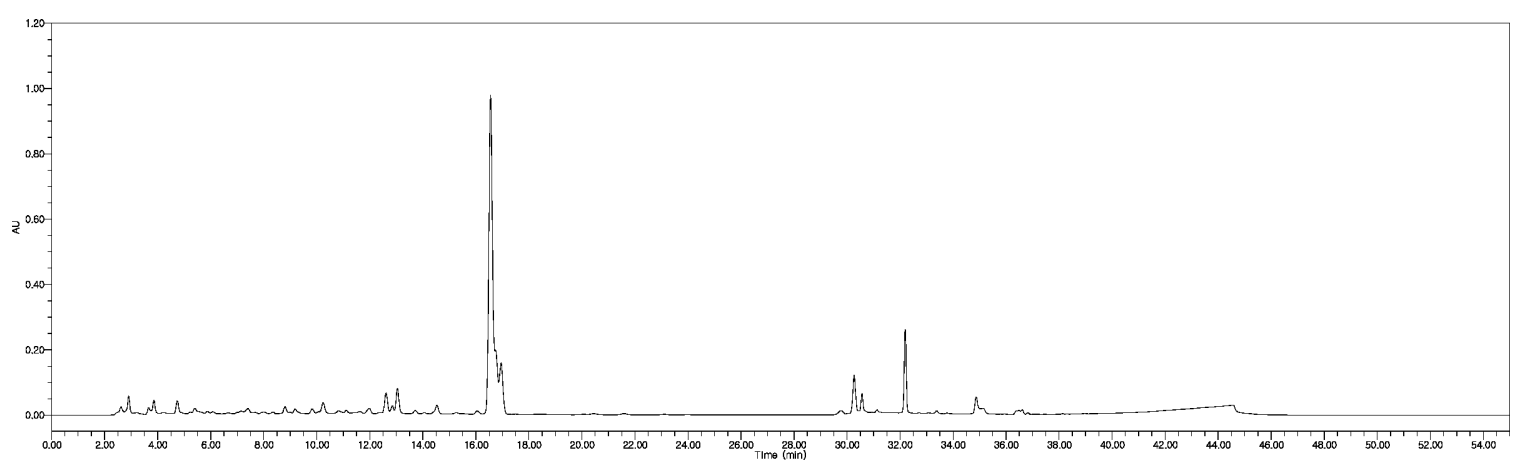

(I)

Fig. 2 Contined

Table 2 Contents of compounds 1-3 in the $\mathrm{MeOH}$ extracts of selected Korean thistles

\begin{tabular}{cccc}
\hline \hline \multirow{2}{*}{ Sample } & \multicolumn{3}{c}{ Content (mg/g extract) } \\
\cline { 2 - 4 } & Cirsimarin (1) & Hispidulin (2) & Cirsimaritin (3) \\
\hline CJMS & $17.65 \pm 0.60$ & $3.31 \pm 0.01$ & $79.73 \pm 0.10$ \\
CJMF & $74.99 \pm 0.04$ & $0.16 \pm 0.00$ & $21.07 \pm 0.01$ \\
CJ & $0.04 \pm 0.00$ & ND & $1.62 \pm 0.00$ \\
CC1 & $9.28 \pm 0.20$ & ND & ND \\
CC2 & $44.77 \pm 0.23$ & ND & ND \\
CC3 & $0.37 \pm 0.00$ & ND & ND \\
CN & $46.75 \pm 0.11$ & ND & ND \\
CS & $73.59 \pm 0.46$ & ND & ND \\
\hline
\end{tabular}

$\mathrm{ND}=$ not detected

consistent with previous studies that investigated on its phytochemistry [14]. The concentration of compounds $\mathbf{1 - 3}$ in CJM varied according to the time of harvest as shown by the differences in flavonoid content between the samples collected in the spring (CJMS) and in the fall (CJMF). Particularly, the concentration of $\mathbf{1}$ was highest in the samples harvested in the spring while that of $\mathbf{3}$ was highest in the fall. This indicates that seasonal variation affects the flavonoid content of CJM, which should be taken into consideration to optimize the yield of these compounds upon harvest. Especially because the reported biological activities of CJM is attributed to the presence of compounds 1-3 in its extracts, and that variations in their yield can have profound effects on the bioactivity of CJM. In our previous research works, we have shown that compounds $\mathbf{1}$ and $\mathbf{2}$ from CJM confer potential therapeutic effects against diabetes, as indicated by its strong inhibitory effects on the polyol pathway which is a major mechanism linked to the pathogenesis of diabetic complications $[13,19]$. Moreover, compounds 1-3 in CJM has also been reported to exhibit beneficial against menopausal symptoms in animal models [18]. Moreover, the results showed that although CJ and CJM belong to the same species, the two varieties showed distinct flavonoid contents in that all three methoxyflavones were present in CJM whereas $\mathbf{2}$ was absent in CJ. The contents of $\mathbf{1}$ and $\mathbf{3}$ were also higher in CJM than in CJ. This indicates that the flavonoid contents of CJ and CJM can be used to distinguish the two varieties similar to a previous study in which $C$. setosum and $C$. japonicum were differentiated from each other based on their flavonoid contents [3].

There have been few studies on the chemical composition of Korean thistles and this study provides new information regarding the distribution and concentration of methoxyflavones in several Korean thistle species. It was observed that compounds 1-3 are the major constituents of CJM and therefore could be cultivated as a source of these compounds for industrial and pharmaceutical applications.

Acknowledgments This work was supported by a grant from Imsil Herbal Medicine Association (2017), Imsil, Korea.

\section{References}

1. Jeong DM, Jung HA, Choi JS (2008) Comparative antioxidant activity and HPLC profiles of some selected Korean thistles. Arch Pharm Res 31: $28-33$

2. Ishida H, Umino $T$, Tsuji $K$, Kosuge $T$ (1987) Studies on antihemorrhagic substances in herbs classified as hemostatics in Chinese medicine. VII on the antihemorrhagic principle in Cirsium japonicum DC.Chem Pharm Bull 35: 861-864

3. Ganzera M, Pocher A, Stuppner H (2005) Differentiation of Cirsium japonicum and C. setosum by TLC and HPLC-MS. Phytochem Anal 16: 205-209

4. Morita N, Shimizu M, Arisawa M (1973) Two new flavone glycosides from Cirsium lineare. Phytochemistry 12: 421-423

5. Park JC, Lee JH, Choi JS (1995) A flavone diglycoside from Cirsium japonicum var. ussuriense. Phytochemistry 39: 261-262

6. Lee WB, Kwon HC, Cho OR, Lee KC, Choi SU, Baek NI, Lee KR (2002) Phytochemical constituents of Cirsium setidens Nakai and their cytotoxicity against human cancer cell lines. Arch Pharm Res 25: 628635

7. Zhang Q, Tu G, Zhao Y, Cheng T (2002) Novel bioactive isoquinoline alkaloids from Carduus crispus. Tetrahedron 58: 6795-6798

8. Liu S, Luo X, Li D, Zhang J, Qiu D, Liu W, She L, Yang Z (2006) Tumor inhibition and improved immunity in mice treated with flavone from Cirsium japonicum DC. Int J Immunopharmacol 6: 1387-1393

9. Yoo YM, Nam JH, Kim MY, Choi JW, Park HJ (2008) Pectolinarin and pectolinarigenin of Cirsium setidens prevent the hepatic injury in rats 
caused by D-galagtosamine via an antioxidant mechanism. Biol Pharm Bull 31: 760-764

10. Han JY, Ahn SY, Kim CS, Yoo SK, Kim SK, Kim HC, Hong JT, Oh KW (2012) Protection of apigenin against kainite-induced excitotoxicity by anti-oxidative effects. Biol Pharm Bull 35: 1440-1446

11. Jin SE, Min BS, Kim BW, Choi JS (2012) Anti-inflammatory activity of Korean thistle Cirsium maackii and its major flavonoid, luteolin-5-Oglucoside. Food Chem Toxicol 50: 2171-2179

12. Chung MJ, Lee S, Park YI, Lee JS, Kwon KH (2016) Neuroprotective effects of phytosterols and flavonoids from Cirsium setidens and Aster scaber in human brain neuroblastoma SK-N-SH cells. Life Sci 148: 173 182

13. Lee J, Rodriguez J, Lee KH, Park JY, Kang KS, Hahm DH, Huh CK, Lee SC, Lee S (2017) Determination of flavonoids from Cirsium japonicum var. maackii and their inhibitory activities against aldose reductase. Appl Biol Chem 60: 487-496

14. Rodriguez J, Lee J, Park JY, Kang KS, Hahm DH, Lee SC, Lee S (2017) HPLC-UV analysis of sample preparation influence on flavonoid yield from Cirsium japonicum var. maackii. Appl Biol Chem 60: 519-525

15. Hasrat JA, De Bruyne T, De Backer JP, Vauquelin G, Vlietinck A (1997) Cirsimarin and cirsimaritin, flavonoids of Microtea debilis (Phytolaccaceae) with adenosine antagonistic properties in rats: leads for new therapeutics in acute renal failure. J Pharm Pharmacol 49: 1150-1156

16. Kavvadias D, Sand P, Youdim K, Qaiser Z, Rice-Evans C, Baur R, Sigel E, Rausch WD, Riederer P, Schreir P (2004) The flavone hispidulin, a benzodiazepine receptor ligand with positive allosteric properties, traverses the blood-brain barrier and exhibits anticonvulsive effects. $\mathrm{Br} \mathrm{J}$ Pharmacol 142: 811-820

17. Quan Z, Gu J, Dong P, Lu J, Wu X, Wu W, Fei X, Li S, Wang Y, Wang J, Liu Y (2010) Reactive oxygen species-mediated endoplasmic reticulum stress and mitochondrial dysfunction contribute to cirsimarininduced apoptosis in human gallbladder carcinoma. Cancer Lett 295: 252-259

18. Park JY, Yun H, Jo J, Baek JY, Lee SC, Choi YJ, Shim JS, Choi HJ, Lee S, Kang KS (2018) Beneficial effects of Cirsium japonicum var. maackii on menopausal symptoms in ovariectomized rats. Food Funct 9: 24802489

19. Rodriguez J, Lee YK, Woo DG, Shim JS, Geraldino PJ, Jacinto S, Lee S (2018) Flavonoids from Cirsium japonicum var. maackii pappus as inhibitors of aldose reductase and their simultaneous determination. Chem Pap 72: 81-88 